there is a useful account of the various inquiries into the case of individual abused children whose cases ended on a tragic note. Moreover, this book prompts both legal and non-legal readers to focus on one of the major questions in the whole debate: to what extent can we control this particularly repulsive evil within our society? At the end of the day one suspects that redesigning of legal responses is not much more than a palliative measure, important, of course, but unlikely to reduce the incidence of abuse. No matter how much we may whip ourselves up into a moral panic over particular allegations (such as those discussed in the Orkney inquiry) or over child abuse as a whole, this does not resolve the basic contradiction: we have created a legal ethic directed towards the protection of children at precisely the same juncture in our social evolution that we have allowed the wholesale destruction of the fragile concept of protected childhood. In the same breath as we say that children are increasingly autonomous young adults and should be allowed to behave as such and be treated (and commercially exploited) as such, we protest at the harm which is done to children. The law's role in resolving this issue is marginal; the roots of the problem go too deep.

ALEXANDER McCALL SMITH, Faculty of Law, University of Edinburgh.

\section{Drawing the line: life, death and ethical choices in an American hospital}

Samuel Gorovitz, 195 pages, New York, 1991, Oxford University Press, $£ 15.00$

This is a book rich in pickings for both the medic and the ethicist, but it provides no easy solutions. It is none the poorer for this, however, and remains highly readable to the end. Gorovitz's observations and experiences over seven weeks in Boston's Beth Israel hospital, where he was referred to as 'the ethics guy', unfold in a series of self-contained chapters. These address a fairly standard range of ethical issues, from abortion and fetal research to those at the other end of life, including DNR orders and living wills, and the quality of care of the very old. Ethical problems arising from economic constraints are considered in the various contexts, rather than taken as a separate issue. Two additional chapters on marketing health care and medical education are particularly pertinent to the American context, but may well be those from which the UK reader has the most to learn.

Gorovitz has used the case study approach, made tolerable by the snappy and often humorous descriptions being interspersed with facts, medical explanation, historical note, political and legal comment, and ethical analysis.

It is this last to which I turn with some disappointment, made greater by the high standard set on other fronts readability, quality of factual information, and the portrayal of very human characters. Readers who are seeking direction and perspective on how the ethical questions raised should best be approached will find themselves guided surely and soundly in a liberal direction, and one embedded unquestioningly in the legal and political status quo in the US (with, however, notable exceptions when the author tends to disagree). On the subject of fetal research Gorovitz asks: 'Can there be any respectable argument against the further medical use of fetal tissue?'. Opponents are characterised as 'driven by a naive passion for simplicity' or those 'whose capacity to reason shuts down when they hear the word "fetus"". His own position seems grounded in the (highly contestable) statement: 'To prevent the doing of good is as wrong as to do harm; indeed it is to do a kind of harm'.

Nevertheless, the book's approach enables the practical difficulties and constraints on these ethical issues to be considered in a manner which may be precluded by a more theoretical analysis. The question of why fundamental ethical tensions arise and are not resolvable in any straightforward way is explained. 'Ethical' decisions may, in fact, have a large political component and where to draw the line is not always clear; indeed, the line to which the title refers is not confined to the moral domain. Gorovitz's ethical choices are set in the US context of political life, laws, funding, the threat of government intervention in monitoring hospital practices, and particular patient care decisions.

It is as well to remember that more philosophically satisfying analyses do not provide better - if any - answers than emerge from Gorovitz's approach. If the ethical analysis is taken as his personal (but informed) comment on his experiences at Beth Israel hospital, they stand above the criticisms made, but remain relative to the US health care system. This need not make them less useful to the person seeking a more rigorous approach, as the discussions (especially on abortion, fetal research, organ transplantation and care of the very old) make some worthwhile contributions to the debates.

This book contains a wealth of information for all interested in health care ethics and is not patronising to the medically trained. The approach is clear and understandable without relying on philosophical explanations of moral theories (there is merely a passing reference to Kant and utilitarianism, and Rawls is described as 'rough going all the way'). It is ordinary morality at work here, with a preference for common-sense examples coupled with analogies; yet there is much to occupy the serious ethicist, even if this results in some criticism. Books which speak to, and more importantly can be heard by, a wide audience including lay persons, medical personnel, administrators and ethicists, must be taken seriously, as the solutions to the ethical choices in hospitals on both sides of the Atlantic do not rest with any one group alone. As Gorovitz says: 'If you are dying, remember that your doctor needs all the help you can provide'.

LESLEY MCTURK, Department of Philosophy, University of Glasgow.

\section{Human dignity and animal well-being}

Mats G Hansson, 210 pages, Uppsala, 1991, Almqvist and Wiksell

International, SEK 150 (£14)

Dr Hansson correctly observes that recent work in biomedical ethics has been dominated by various forms of utilitarian calculation. Nurses, doctors, hospital managers and government ministers are all encouraged to believe, as a matter of course, that that act is right that does the most good. The good such acts do, of course, cannot be determined even in part by whether the chosen act was rightly, justly, faithfully or decently performed. To do right must simply be to increase pleasure and decrease pain, or to satisfy as many 
preferences as possible. Notions like the sanctity or dignity of human (or other) life fall away. Anything less than utilitarian calculation of "quality life saved' must be superstition, culminating (for example) in Peter Singer's willingness to encourage abortion of, or experimentation on, those whose lives would be less worth living (treating 'potential people' very much as more traditional moralists have thought it right to treat non-human animals).

Hansson gives details of several medical or quasi-medical procedures about which questions can be raised (abortion, the use of fetal tissue, alleviation of infertility, embryo research, gene therapy, eugenics and transgenic experimentation). $\mathrm{He}$ carefully distinguishes (as others have not always done) the questions that can be asked in addition to straightforwardly consequentialist ones. After a brief and critical exposition of Singer's (and Hare's) utilitarianism, he chooses to develop a Kantian approach, drawing on a wider range of Kant's writing than is usual, and developing the argument (as he admits) in ways that Kant himself could not really have admitted. Unlike Kant, for example, he is sure that we do have duties toward non-human animals rather than only towards humanity. He draws on Carol Gilligan's work to suggest that Justice and Care are both important in Kantian perspective. Although human beings have a special dignity, duties of beneficence toward animals (as intrinsically valuable) are actually more extensive, he suggests, than Singer's defeasible duty not to cause them pain. 'An eagle might not feel pain if we were to expose it to chemical waste like mercury but it is highly detrimental to its ability to live according to its purposiveness' (p 149). It is possible that Hansson could have profited from reading Rollin or Regan on this sort of point.

Finally, he formulates five, quite lengthy, maxims that may help us to cope with the sort of biomedical issues he has previously described. Crucial terms in these maxims include: what is essential for a human being's physical, psychical and moral existence; care; integrity; 'physical, psychical and social well-being'; and 'stewardship of values in a purposive whole'. This last term reflects Hansson's concern for ecological values and for the intrinsically valuable beauty of those wholes. Human beings are superior to others in that they alone can take responsibility, but their duties are to a purposiveness which may conflict with their own sensible interests. In brief, he concludes that a suitably expanded Kantian ethics does provide a theoretical basis for a less consequentialist approach, respecting the autonomy and integrity of individual persons (including potential persons, which are more than merely things that might possibly end up as persons), and affording more protection to non-human animals than Singer's own, animal liberationist principles. The whole is a distinguished, and unusual, contribution to biomedical ethics and Kantian scholarship.

STEPHEN R L CLARK, Department of Philosophy, Liverpool University.

\section{Applied philosophy, morals and metaphysics in contemporary debate}

Edited by Brenda Almond and Donald Hill, 334 pages, London, 1991, Routledge, £10.99

This anthology comprises twenty-eight articles divided among the following topics: The environment; Personal relationships; Terrorism, war and confict; Justice and equality; and Ethics and medicine. The articles were all originally published in the fournal of Applied Philosophy, from whose editorial staff come the co-editors of this anthology. The purpose of this anthology is not at all clear. Two of the most important functions of anthologies are: first, to assemble important papers on a subject or by an individual that were previously unpublished or widely scattered and second, to assemble articles useful for teaching. Since the articles were all published in the same journal, the anthology does not fulfil the first function. Nor is it entirely apt for the second function: seminal articles from other journals that should be required reading are omitted. What the anthology really seems to be is a 'Best of ...' collection for promoting applied philosophy in general and the fournal of Applied Philosophy in particular.
Because of limitations of space, I shall confine the rest of my discussion to the section on ethics and medicine. In general, while the seven articles in this section are competent, none sparkles. Four of the articles concern either the beginning or end of life. E Page argues that gametes should be transferable while embryos should not: transferring embryos would violate the principle that children should not be transferred, while transferring gametes would not. He takes it to be a consequence of this that women who have agreed to be surrogates prior to conception should be held to the agreement. J Trusted bases a compelling criticism of this conclusion on the fact that surrogacy involves more than the incubation of an embryo. A Holland criticises the view that for the first two weeks after conception a fertilised egg is not an embryo and, therefore, not human. This view rests on the observation that for about two weeks the material making up the embryo is not distinct from the material making up the placenta and fetal membranes and it is still possible for the material to develop into two distinct embryos (identical twins). In one of the most interesting articles, A Browne discusses the vagueness of the notion of death and argues that there is no utility in formulating a general stipulative definition of death. Instead he suggests that we would be better off formulating different criteria of death for different purposes.

The remaining three papers in this section deal with a variety of topics. A description of the philosophical issues involved in practical decision-making in a clinical setting is given by D Moros, R Rhodes, B Baumrin and J Strain. $S$ Marshall argues that the right to privacy is neither reducible to other rights nor justified on utilitarian grounds, but is founded on the requirement that a person's autonomy be respected. $\mathbf{R}$ Chadwick rejects the view that a prohibition against selling body parts can be justified on the Kantian ground that persons have duties to themselves, but argues that it can be justified by appeal to a general obligation to promote human flourishing.

ROBERT L FRAZIER, Visiting Assistant Professor of Philosophy, Virginia Commonwealth University, USA. 